\title{
REPAIR OF ANTERIOR LEAFLET PROLAPSE: CHORDAL TRANSFER IS SUPERIOR TO CHORDAL SHORTENING
}

Nicholas G. Smedira, MD

Raphael Selman, MD

Delos M. Cosgrove, MD

Patrick M. McCarthy, MD

Bruce W. Lytle, MD

Paul C. Taylor, MD

Carolyn Apperson-Hansen, MStat

Robert W. Stewart, MD

Floyd D. Loop, MD
Several techniques are currently used to repair anterior leaflets with elongated or ruptured chordae. To evaluate the efficacy of these techniques, we analyzed the case histories of 108 patients operated on from 1989 through 1992 with degenerative mitral valve disease and prolapse of the anterior leaflet. The mean age was $59 \pm 15$ years (range 18 to 87 years) and $74(69 \%)$ were male. Methods: Chordal shortening was performed in 31 $(29 \%)$ and chordal transfer in $77(71 \%)$ of the repairs. Of the transfers, 58 $(75 \%)$ were from the posterior to the anterior leaflet and $16(21 \%)$ were from the secondary to the primary position of the anterior leaflet. Three patients had both types of transfers. Seventy-one $(66 \%)$ patients had isolated repairs and the remainder had associated procedures. The degree of preoperative mitral regurgitation was $3+$ or greater for $107(99 \%)$ of the patients, mean 3.4 for shortening and 3.7 for transfer. Results: Four $(\mathbf{4 . 0} \%)$ hospital deaths occurred, none after isolated repair. Follow-up of hospital survivors was $100 \%$ complete at a mean of 4.0 years. A total of 421 patient-years of follow-up were available for analysis. There were seven late deaths, for a 5-year actuarial survival of $93 \%$. Eleven patients underwent reoperation for recurrent mitral regurgitation. Five-year actuarial freedom from reoperation was $90 \%-96 \%$ after chordal transfer and $74 \%$ after chordal shortening, $p=\mathbf{0 . 0 0 3}$. Independent predictors for reoperation include chordal shortening and preoperative New York Heart Association functional class III or IV. The mechanism of valve failure in six of seven patients undergoing reoperation after chordal shortening was rupture of the previously shortened chordae. Conclusions: We conclude that chordal transfer is superior to chordal shortening, providing a more predictable correction of mitral regurgitation and a lower incidence of reoperation. Reoperations after chordal shortening are a result of rupture of the previously shortened chordae. (J Thorac Cardiovase Surg 1996;112:287-92)
C orrection of anterior leaflet prolapse has been more difficult than reconstruction of the posterior leaflet. Poor results after anterior leaflet resection led Carpentier in 1983 to introduce the tech-

From The Cleveland Clinic Foundation Department of Thoracic and Cardiovascular Surgery, Cleveland, Ohio.

Read at the Twenty-first Annual Meeting of The Western Thoracic Surgical Association, Coeur d'Alene, Idaho, June 21-24, 1995.

Received for publication June 21, 1995; revisions requested Feb. 8, 1996; revisions received April 2, 1996; accepted for publication April 3, 1996.

Address for reprints: Nicholas G. Smedira, MD, Department of Thoracic and Cardiovascular Surgery, The Cleveland Clinic Foundation, 9500 Euclid Avenue, F25, Cleveland, OH 44195.

Copyright (C) 1996 by Mosby-Year Book, Inc.

$0022-5223 / 96 \$ 5.00+0 \quad \mathbf{1 2 / 6 / 7 3 9 1 5}$ nique of chordal transposition for repair of ruptured anterior chordae. ${ }^{1,2}$ Chordal shortening was originally the preferred method for handling elongated chordae, but a number of surgeons have applied chordal transfer in this situation with excellent short-term results. ${ }^{3-6}$ The relative effectiveness of these techniques is unknown. To address this issue, we examined our experience with degenerative prolapse of the anterior leaflet repaired by either chordal transfer or chordal shortening.

\section{Patients and methods}

From 1989 through 1992, 188 patients underwent reconstruction of the anterior mitral leaflet for mitral regurgitation (MR). Myxomatous changes resulting in chordal elongation or rupture were present in 127 patients, with 108 undergoing repair by chordal transfer or shortening. This group forms the basis of the study. 
Table I. Preoperative demographics

\begin{tabular}{lcccc}
\hline Variable & $\begin{array}{c}\text { Total } \\
(n=108)\end{array}$ & $\begin{array}{c}\text { Transfer } \\
(n=77)\end{array}$ & $\begin{array}{c}\text { Shortening } \\
(n=31)\end{array}$ & $\begin{array}{c}p \\
\text { Value }\end{array}$ \\
\hline Age (yr) & $59 \pm 15$ & $59 \pm 15$ & $62 \pm 14$ & NS \\
Male (\%) & 69 & 58 & 72 & NS \\
NYHA FC III (\%) & 79 & 80 & 78 & NS \\
Normal/mild LV & 69 & 68 & 70 & NS \\
$\quad$ dysfunction (\%) & & & &
\end{tabular}

NYHA FC, New York Heart Association functional class; $L V$, left ventricular; $N S$, not significant.

Preoperative descriptors for patients undergoing anterior leaflet repair are shown in Table I. The two groups were similar with regard to age, gender, preoperative New York Heart Association (NYHA) functional class, preoperative left ventricular function, and severity of MR.

All patients had intraoperative echocardiograms before and after valve reconstruction. MR was graded from 0 to $4+$ on the basis of the distance the systolic jet extends from the valve and the maximum percentage of mosaic Doppler color in the left atrium. ${ }^{7}$ The preoperative designation of degenerative MR was confirmed by the operating surgeon. Mitral reconstruction was combined with another intervention in $37(34 \%)$ patients: $23(62 \%)$ had coronary revascularization, $11(30 \%)$ had aortic valve repair or replacement, and $3(8 \%)$ had tricuspid valve annuloplasty.

Chordal transfer was performed in 77 patients. A segment of the posterior leaflet was transferred to the anterior leaflet in $58(75 \%)$ patients. Transfer of a secondary chorda to the free edge of the anterior leaflet was used to repair the valve in $16(21 \%)$ patients (Fig. 1). Three (4\%) patients had both secondary chordal transfer and posterior leaflet transfer. An annuloplasty was performed in $59(77 \%)$ of the chordal transfers: $45(77 \%)$ of the posterior to anterior transfers and $13(81 \%)$ of the secondary chordae to free edge transfers.

In 31 patients elongated chordae were shortened by burying the chordae in a papillary muscle trench as described by Carpentier. ${ }^{1}$ As part of this repair an annuloplasty was performed in $30(97 \%)$ and concomitant posterior leaflet resection in $12(39 \%)$.

Follow-up was $100 \%$ complete at an average of 4 years. A total of 421 patient-years of follow-up were available for analysis. Operative reports were examined on all patients undergoing reoperation outside our institution. Late postoperative echocardiograms were obtained in $59(63 \%)$ of the 93 patients surviving the hospitalization and not undergoing reoperation.

Statistical analysis. Results are presented as the mean \pm the standard deviation. When appropriate, results of $\chi^{2}$ or $t$ tests are presented.

Kaplan-Meier (Pro Life Test, SAS Institute, Inc., Cary, N.C.) estimates and step functions were generated for survival and freedom from reoperation. ${ }^{8}$ To investigate intermediate-term freedom from reoperation, we included only hospital survivors in the analysis. Results at 5 years are probabilities \pm the standard error.

Age, gender, primary operation versus reoperation, preoperative NYHA functional class, isolated versus com- bined mitral valve repair, and type of repair were examined by univariate analysis with the use of a log rank and a Wilcoxon statistic (Pro Life Test, SAS Institute) to examine their effect on survival and freedom from reoperation. Stepwise Cox proportional hazard models (Proc Phreg, SAS Institute) were applied to identify independent predictors of death and reoperation.

\section{Results}

Four (4\%) hospital deaths occurred, two $(6 \%)$ in the shortening group and two $(3 \%)$ in the transfer group. All four deaths occurred in patients having concomitant coronary artery bypass grafting. No deaths occurred in patients undergoing isolated mitral valve repair. Reoperation for bleeding was necessary in six patients, and one patient had a postoperative stroke.

After reconstruction, MR was significantly more prevalent in the shortening group ( $7 / 31$ or $22 \%$ with grade 2 to $3+M R)$ than in the transfer group (3/77 or $4 \% ; p=0.01$ ).

No late postoperative thromboembolic events or episodes of endocarditis occurred. At a mean of 4 years after repair, $26(90 \%)$ patients in the shortening group and $60(91 \%)$ patients in the transfer group were in NYHA functional class I.

Seven late deaths occurred, for a 5-year actuarial survival of $93 \% \pm 3 \%$. There was no significant difference in survival between patients undergoing shortening or transfer, with one patient in the shortening group and six patients in the transfer group dying during the follow-up period. Stepwise Cox proportional hazards analysis identified age as an independent predictor for late postrepair death.

Eleven patients, four after transfer and seven after shortening, required reoperation on the mitral valve at a mean of $16 \pm 19$ months (range 3 to 62 months) after the first operation. The 5-year actuarial freedom from reoperation was $90 \% \pm 3 \%$. Patients undergoing chordal transfer fared significantly better than those undergoing chordal shortening: $96 \% \pm 2 \% 5$-year freedom from reoperation in the chordal transfer group compared with $74 \% \pm$ $8 \%$ 5-year freedom from reoperation after chordal shortening ( $p=0.003$ ) (Fig. 2).

Univariate analysis identified three predictors of reoperation-postoperative NYHA class III or IV, postoperative MR grade 2+ or more, and chordal shortening. Stepwise Cox proportional hazards analysis of these variables found both preoperative NYHA functional class III or IV and shortening techniques to be independent predictors of reoperation (Table II). 


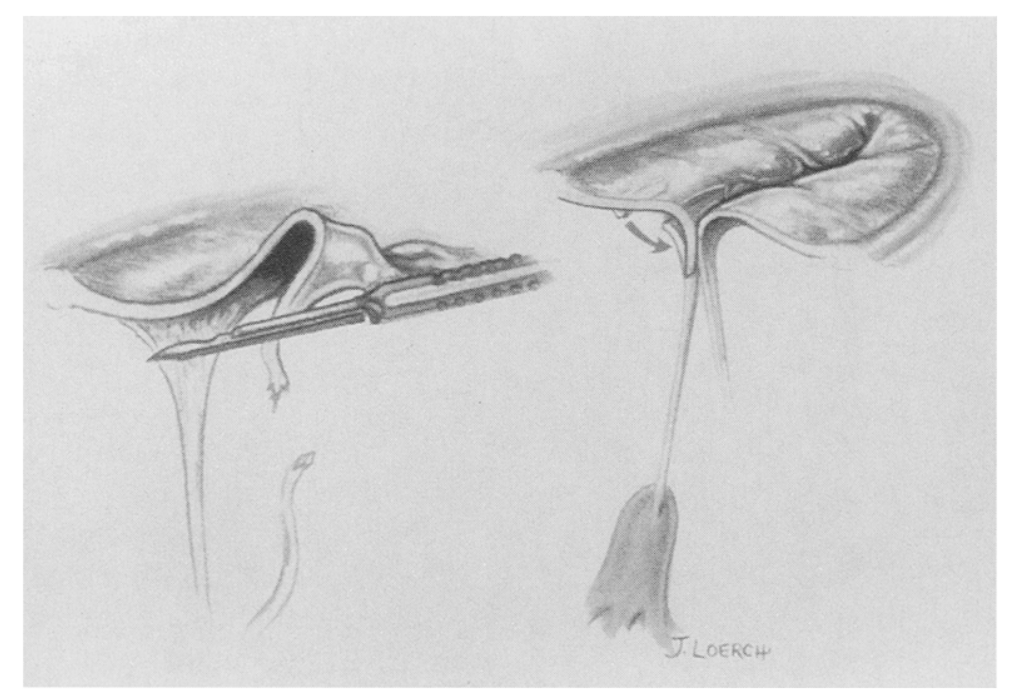

Fig. 1. A secondary chorda is transferred to the free edge of the anterior leaflet.

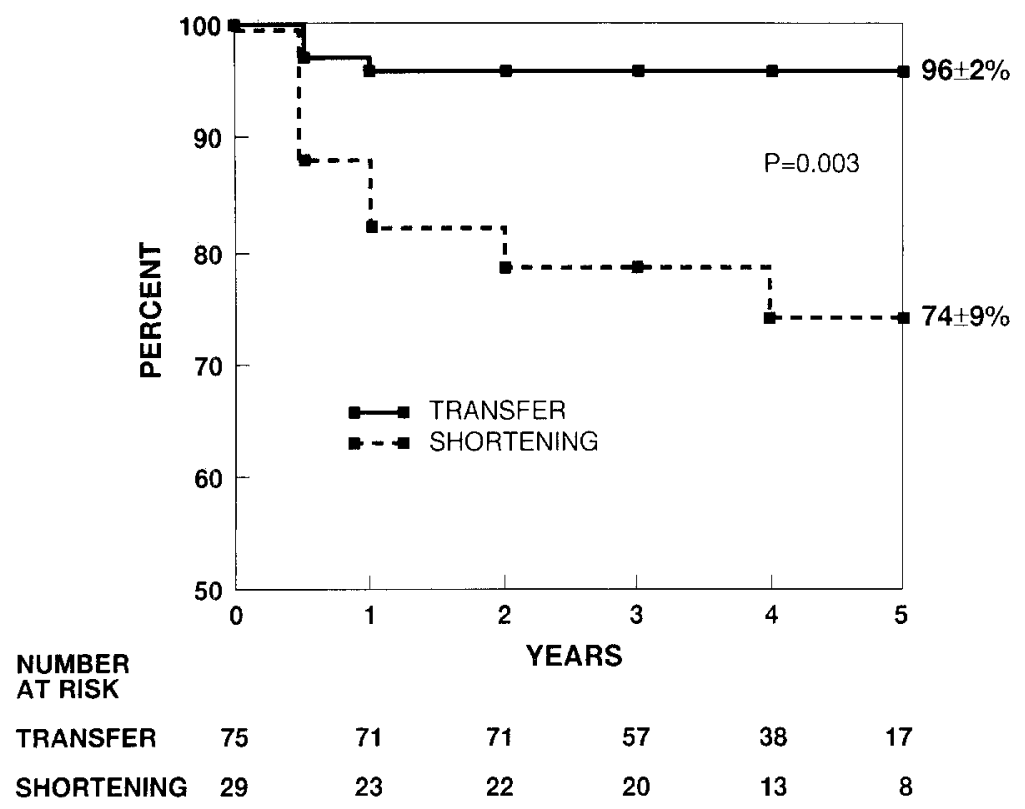

Fig. 2. Five-year actuarial freedom from reoperation. The difference is significant $(p=0.003)$.

At reoperation, six of the seven previously shortened chordae had ruptured at the papillary muscle head (Fig. 3). Two reoperations after transfer were for dehiscence of the suture line at the site of posterior leaflet resection and one was the result of separation of the transferred posterior segment from the anterior free edge.

Echocardiograms were available for analysis in 59 $(63 \%)$ of the 93 hospital survivors not undergoing
Table II. Stepwise Cox proportional hazards analysis for reoperation

\begin{tabular}{cccc}
\hline & \multicolumn{4}{c}{$\begin{array}{c}95 \% \\
\text { Risk } \\
\text { Variable }\end{array}$} & $\begin{array}{c}\text { Confidence } \\
\text { intervals (\%) }\end{array}$ & $\begin{array}{c}p \\
\text { Value }\end{array}$ \\
\hline Cordal shortening & 4.8 & $1.4,16.4$ & 0.001 \\
$\begin{array}{c}\text { Preoperative NYHA } \\
\text { class III/IV }\end{array}$ & 4.7 & $1.4,15.4$ & 0.005
\end{tabular}

NYHA, New York Heart Association. 


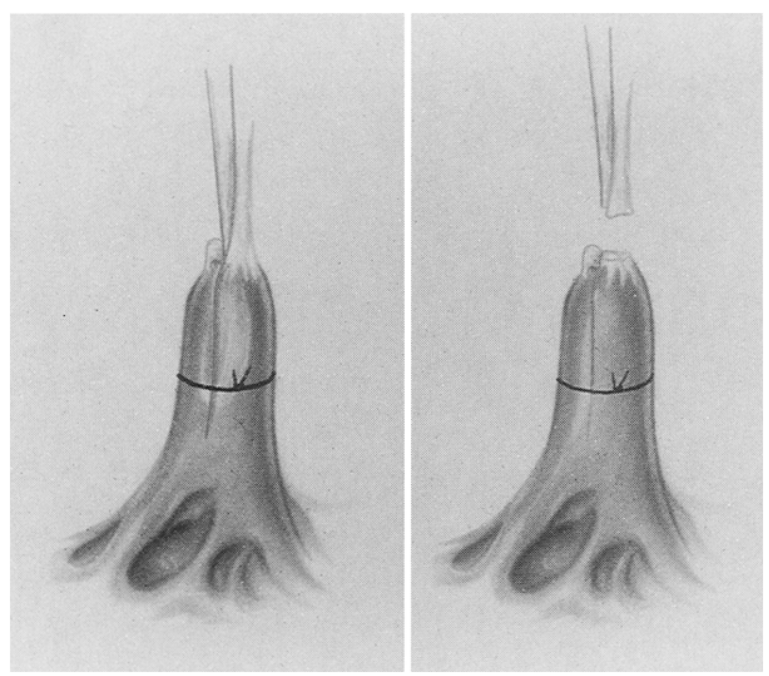

Fig. 3. Findings at reoperation after failed chordal shortening. The shortened chorda has ruptured at its insertion into the papillary muscle.

reoperation at a mean of 3.5 years after the repair. Follow-up echocardiograms revealed a mean of $1.2+$ MR: $1.2+$ for transfer and $1.3+$ for shortening (no significant difference).

\section{Discussion}

Reconstruction of an insufficient mitral valve is superior to mitral valve replacement, with lower operative mortality, better preservation of ventricular function, longer survival, fewer thromboembolic complications, and reduced risk of endocarditis. ${ }^{9}$ With increased experience and longer follow-up, it became obvious that the cause of the MR and the complexity and type of repair significantly influenced the durability of the repair., $9-11$

The management of a prolapsing anterior mitral leaflet has evolved from a hesitancy to perform any type of reconstruction, to limited leaflet resections, and finally to a number of reconstructive approaches including pericardial chordae, polytetrafluoroethylene chordae, chordal shortening, and chordal transfer. ${ }^{10,12-16}$ Chordal transfer has generally been reserved for ruptured anterior chordae, but its relative technical ease has let to a wider application. Three series of chordal transfer with excellent short-term results have been published, but a direct comparison between chordal shortening and transfer has not been done. ${ }^{4-6}$ Thus the ideal approach to myxomatous anterior leaflet prolapse remains unclear.

This series focused on degenerative prolapse of the anterior leaflet repaired by either chordal short-
Table III. Chordal transfer repair of anterior leaflet prolapse

\begin{tabular}{lcccc}
\hline $\begin{array}{c}\text { First } \\
\text { author }\end{array}$ & Date & Disease & $\begin{array}{c}\text { No. } \\
\text { of } \\
\text { patients }\end{array}$ & $\begin{array}{c}\text { Freedom } \\
\text { from } \\
\text { reoperation }\end{array}$ \\
\hline Lessana $^{4}$ & 1985 & Mixed & 39 & $97 \% \pm 5 \%$ at $4 \mathrm{yr}$ \\
Salati $^{5}$ & 1992 & Degenerative & 48 & $92 \% \pm 5 \%$ at $3 \mathrm{yr}$ \\
Uva $^{6}$ & 1993 & Mixed & 44 & $95 \%$ at $3 \mathrm{yr}$ \\
\hline
\end{tabular}

ening or transfer. We were careful to include only patients with echocardiographic and pathologic evidence of myxomatous disease. Despite its technical difficulty, this type of repair was accomplished safely without hospital mortality in patients undergoing isolated valve repair.

Reoperation was more frequent after shortening than transfer in this series. Univariate analysis identified preoperative NYHA functional class, chordal shortening, and postoperative MR as risk factors for reoperation. These observations confirm two earlier reports from our institution that found residual MR after repair, failure to perform a posterior annuloplasty, and chordal surgery to be associated with an increased risk of reoperation. ${ }^{17,} 18$ Almost all shortening procedures in the current series included an annuloplasty, thus negating this as a factor. More patients undergoing chordal shortening had residual MR of grade $2+$ or more after repair and almost $30 \%$ of all patients with postrepair MR of grade 2 or more required reoperation. However, after stepwise hazard analysis only shortening and preoperative NYHA functional class III or IV were statistically significant risk factors for reoperation. Further investigation will be necessary to determine if chordal shortening is a risk factor for reoperation independent of residual MR. When examined at reoperation, six of the seven shortened chordae had ruptured at the site of insertion into the papillary muscle.

These elongated chordae are by definition structurally weakened with loss of the central collagen core and are likely predisposed to elongation or rupture. ${ }^{19}$ It is unknown to what degree stress on the chordae is changed after shortening and what effect residual MR has on the generated stress. The operation is technically more difficult, and it may be that the combination of an imperfectly shortened, inherently weak chorda is at increased risk for rupture. The relatively early and rapid progression to severe MR in the failed repair group would support this contention. 
Chordal transfer is reproducible and durable and has become our preferred method of repairing anterior leaflet prolapse. Our 5-year 96\% freedom from reoperation after chordal transfer compares favorably with other published series (Table III). The reason chordal transfer is more durable than chordal shortening is unknown. Posterior chordal transfer usually includes multiple primary and secondary chordae and may, therefore, have a mechanical advantage to reduce and evenly distribute the generated stress. Supporting this theory is a recent finite element analysis of stress on chordae adjacent to a ruptured chordae. ${ }^{20}$ Only after four artificial chordae were used for reconstruction was stress on the nonruptured chordae reduced to normal levels.

Our study is limited by its retrospective and nonrandomized nature with potentially subtle selection bias in choosing which type of reconstruction to perform. Despite this, the difference in durability between chordal transfer and shortening is substantial. Chordal transfer is our preferred method for repairing degenerative prolapse of the anterior leaflet.

\section{REFERENCES}

1. Carpentier A. Cardiac valve surgery-the "French correction." J Thorac Cardiovasc Surg 1983;86:323-337.

2. Carpentier A, Chauvaud S, Fabiani JN, Deloche A, Relland J, Lessana A, et al. Reconstructive surgery of mitral valve incompetence. J Thorac Cardiovasc Surg 1980;79:338-48.

3. Deloche A, Jebara VA, Relland JYM, Chauvaud S, Fabiani JN, Perier $\mathrm{P}$, et al. Valve repair with Carpentier techniques: the second decade. J Thorac Cardiovasc Surg 1990;99:9901002 .

4. Lessana A, Escorsin M, Romano M, Ades F, Vergoni W, Lorenzoni $D$, et al. Transposition of posterior leaflet for treatment of ruptured main chordae of the anterior mitral leaflet. J Thorac Cardiovasc Surg 1985;89:804-6.

5. Salati M, Scrofani R, Fundaro P, Cialfi A, Santoli C. Correction of anterior mitral prolapse. J Thorac Cardiovasc Surg 1992;104:1268-73.

6. Uva Ms, Grare P, Jebara V, et al. Transposition of chordae in mitral valve repair. Circulation 1993;88:35-8.

7. Cosgrove DM, Stewart WJ. Mitral valvuloplasty. In: O'Rourke RA, Crawford MH, editors. Current Problems in Cardiology. Chicago: Year Book, 1989;14:353-416.

8. Cox DR, Oares D. Analysis of survival data. New York: Chapman and Hall, 1984.

9. Yun KL, Miller DC. Mitral valve repair versus replacement. Cardiol Clin 1991;9:315-27.

10. Lessana A, Carbone C, Romano M, Palsky E, Quan YH, Escorsin E, et al. Mitral valve repair: results and the decisionmaking process in reconstruction. J Thorac Cardiovasc Surg 1990;99:622-30.

11. David TE, Armstrong S, Sun Z, Daniel L. Late results of mitral valye repair for mitral regurgitation due to degenerative disease. Ann Thorac Surg 1994;56:7-14.
12. Cohn LH, Couper GS, Aranki SF, Rizzo RJ, Kinchla NM, Collins JJ. Long-term results of mitral valve reconstruction for regurgitation of the myxomatous mitral valve. J Thorac Cardiovasc Surg 1994;107:143-51.

13. David TE, Bos J, Radkowski H. Mitral valve repair by replacement of chordae tendineae with polytetrafluoroethylene sutures. J Thorac Cardiovasc Surg 1991;101:495-501.

14. Orszulak TA, Schaff HV, Danielson GK, Piehler JM, Pluth JR, Frye RL, et al. Mitral regurgitation due to ruptured chordae tendineae. J Thorac Cardiovasc Surg 1985;89:491-8.

15. Gregory F, Takeda R, Silva S, Facanha L, Meier MA. A new technique for repair of mitral insufficiency caused by ruptured chordae of the anterior leaflet. J Thorac Cardiovasc Surg 1988;96:765-8.

16. Frater RWM, Gabbay S, Shore D, Factor S, Strom J. Reproducible replacement of elongated or ruptured mitral valve chordae. Ann Thorac Surg 1983;35:14-28.

17. Fix J, Isada L, Cosgrove D, Miller DP, Savage R, Blum J, et al. Do patients with less than "echo-perfect" results from mitral valve repair by intraoperative echocardiography have a different outcome. Circulation 1993;88:39-48.

18. Marwick TH, Stewart WJ, Currie PJ, Cosgrove DM. Mechanisms of failure of mitral valve repair: an echocardiographic study. Am Heart J 1991;122:149-56.

19. Braunwald E. Valvular heart disease. In: Braunwald E, editor. Heart disease: a textbook of cardiovascular medicine. 4th ed. Philadelphia: WB Saunders, 1992:1030.

20. Reimink MS, Kunzelman KS, Verrier ED, Cochran RP. Artificial chordae tendineae and stresses in the mitral valve: a finite element analysis. ASAIO J 1995;41(Suppl. Jan-March 1995):26.

\section{Discussion}

Dr. Hillel Laks (Los Angeles, Calif.). The problem of the anterior leaflet is a special one with mitral valve repair. In many large series including the one from Tyrone David, about half of the patients have only a posterior leaflet problem, about a quarter anterior and posterior, and only one quarter predominantly an anterior leaflet problem. In the past, dealing with the anterior leaflet has proved somewhat difficult. Carpentier described a technique of triangular resection with results that were not terribly good, and others have tried this with mixed results. Coleman, Spencer, and Rossi reported on the New York experience and found that there was no difference in mitral valve repairs whether the anterior leaflet had to be addressed or not. However, they did confirm your finding regarding shortening versus transfer: When the anterior leaflet was treated with a shortening of chordae they had an $11 \%$ failure rate versus only a $2.4 \%$ failure rate with chordal transfer.

You did not mention the issue of suspension of the anterior leaflet with artificial chordae. Is this is something that you are now doing.

Dr. Smedira. We do not use polytetrafluoroethylene chordae. We are aware that Dr. David and others have had excellent results handling anterior leaflet prolapse with that technique, but we prefer to use autologous tissue if at all possible. We do not have any experience with artificial chordae.

Dr. Laks. Were any of these valves treated with triangular resection as part of the repair? 
Dr. Smedira. Not in the anterior leaflet.

Dr. Laks. It seemed that in the shortening group $22 \%$ of the patients had at least moderate MR in the early postoperative period, whereas this was not the case in the transfer group. This would imply that at the time of the operation the shortening technique did not address the problem with the valve. It seems that if you leave a valve with significant $\mathrm{MR}$ in which chordae are depended on to provide support, you are then putting a large amount of tension on a single isolated chorda. Because of this excessive tension, the chorda may rupture. Perhaps we should conclude that shortening per se may be effective but has to be part of a strategy that provides good tissue apposition and a competent valve.

Dr. Smedira. I think that is a reasonable conclusion. We have published two papers that have said just that: If there is residual MR after repair, there is an increased risk for reoperation. In our univariate analysis, residual MR was a risk factor for reoperation. When those factors were analyzed by a stepwise regression analysis, however, that factor fell out leaving only chordal shortening and NYHA preoperative class. This suggests that with or without residual $M R$ the technique itself is more prone to reoperation. However, I think we would concur that an optimal repair with little or no MR is the ideal standard.

Dr. Laks. The other issue is that the most difficult valve repairs are those in which there is prolapse of both the anterior and posterior leaflets. I would assume that in those cases chordal transfer of the adjacent posterior leaflet would not be possible. Therefore, there could be some selection in that the very worst cases were treated with shortening as opposed to a chordal transfer because of combined prolapse.

Dr. Smedira. I do not have the exact numbers, but roughly $35 \%$ of the patients in the chordal transfer group had ruptured anterior chordae and around $40 \%$ of these patients had posterior leaflet prolapse. The basal chorda of the prolapsing segment of the posterior leaflet was then used as part of the repair, negating the free-edge chordae. Thus a number of the patients did have bileaflet prolapse and still underwent the transfer technique.

Dr. Laks. As a final comment I would like to state my own support of the use of artificial chordae. For many valves in which there is stretching of the leaflet with absence of chordae and combined prolapse of the anterior and posterior leaflets, the use of artificial chordae has given excellent results. We have been using polytetrafluoroethylene chordae for about 2 years. This material provides the ability to use multiple chordae, as many as 14 , to support the anterior and posterior leaflets and to avoid triangular resections and the transfer of chordae, which has its risks. In fact, I think two of your cases of transfer resulted in disruption of the posterior leaflet.

Dr. Smedira. Again, as I mentioned earlier, it has been our preference to use autologous tissue, but the artificial chordae have had excellent long-term results.

Moderator. How tight do you tie them, Hill?

Dr. Laks. The surgeon is limited by two very important things in how tight to make a chord. The first is that you have to get good apposition of the two leaflets. This has been shown to reduce the tension on the chordae. Secondly, you have to distribute the tension among as many chordae as possible. This limits you as to how tight an individual chord can be made. One of the big advantages of the artificial chordae is that by using as many as 10 chordae of an appropriate length, you can distribute this tension among a larger number of chordae. To answer your question, I think how tight depends on two thingsleaflet apposition and distribution of tension among multiple chordae.

Dr. Karyn Kunzelman (Seattle, Wash.). We have developed a model to answer some of those questions that are coming up related to replacing the chordae. When we looked at prolapse with the model, we found that the tension of the chordae adjacent to the area of prolapse was nearly three times higher than it was in the normal state. In reference to your particular study, if you then shorten these chordae, which are already under abnormal tension, you are increasing that tension even more. However, if you transfer the chordae from the opposite leaflet, those chordae have most likely been under normal tension. Would you comment on that and on whether it tends to support what your study shows?

Dr. Smedira. I quoted your work but I looked at it slightly differently. I think one of the reasons the chordal transfer may be more durable is the fact that when you do do a transfer you usually include multiple chordae. In your study it took about four artificial chordae to reduce the stress on the unsupported chordae back toward normal. With chordal shortening, you shorten a pathologically abnormal chorda, and again you may not be able to get the exact measurement. The transferred segment has multiple chordae that would probably more evenly distribute and control the amount of stress. So I agree with you. I think that might be a factor. 